\title{
El tabú del franquismo vivido en la narrativa de Mendoza, Marías y Muñoz Molina
}

\author{
Maarten Steenmeijer
}

\section{Introducción}

Varios años después de la muerte de Franco (el 20 de noviembre de 1975), muchas calles españolas todavía llevaban el nombre del dictador y seguía intacto el ostentoso símbolo de la Falange en los muros de muchísimos pueblos. ¿Por qué no habían desaparecido, junto con el viejo sistema político, estos residuos de la dictatura? Quizás para no ofender a los millones de adeptos de Franco que seguían recordando con afecto al dictador y añoraban "los cuarenta años de paz". O quizás fuera por temor a la extrema derecha, de cuyo poder y combatividad España se percató bruscamente en la noche del 23 de febrero de 1981. Pero lo más probable es que fuera por indiferencia: Franco no era un tema como para enfadarse, sino que se había convertido en un fenómeno insignificante, anodino.

Se trata de una actitud que está estrechamente vinculada al proceso de modernización que, según parecía, había llevado al país a un estado de euforia sin precedentes: por fin los españoles eran libres, por fin eran europeos, por fin eran modernos. Estaban demasiado ocupados con el futuro como para preocuparse del pasado. También el ritmo acuciante en que se producían los cambios contribuyó a que el pasado fuera desapareciendo de la vista con una asombrosa velocidad. Hasta el punto de que en la prensa democrática aparecieron noticias alarmantes diciendo que, para muchos jóvenes crecidos en la democracia, Franco había llegado a tener el mismo status que, por ejemplo, Carlos I, es decir, era un personaje que no tenía nada que ver con el tiempo en que vivían, sino que pertenecía a un pasado remoto.

Esta indiferencia o negligencia no era sólo el producto de la transición sino que, en realidad, se había implantado ya en el periodo 
en que España, a pesar de todos los esfuerzos de Franco para mantener cerrado el país, iba entablando contactos con la cultura de la libertad que reinaba al norte de los Pirineos, un proceso inevitable e irreversible debido a, entre otros factores, la televisión (que, gracias a la creciente prosperidad, hacía su aparición en muchos hogares), a los turistas (cuyo número iba aumentando de forma espectacular) y a los cientos de miles de emigrantes españoles que durante las vacaciones traían sus experiencias, observaciones, impresiones e historias "europeas" a su tierra.

Por todo ello las generaciones que habían nacido y crecido en la dictadura tuvieron en perspectiva otra realidad que aquella en la que vivían. Así pudieron desarrollar una forma singular de libertad-en-laopresión cuyas características principales eran un altivo desprecio por la propia cultura y, al mismo tiempo, un extraordinario interés y aprecio por todo lo que venía de fuera. Se trata de una mentalidad que iba a arraigar profundamente y que sigue vigente hasta el día de hoy. Es significativo en este contexto, por ejemplo, que no fuera un español sino un inglés quien escribió la primera biografía exhaustiva de Franco (Preston, 1993).

Nadie duda de que la Guerra Civil y el franquismo fueron un desastre para la literatura. Las razones son muchas: la censura, la falta de una infraestructura, la muerte de algunos de los valores más importantes durante la Guerra Civil (García Lorca, Machado, Unamuno, Valle-Inclán) y el exilio de la mayoría de los autores que habían sobrevivido la guerra. Así se cortó el importante y prometedor proceso de modernización que vivió la literatura española en las primeras décadas del siglo veinte, y se quedaron huérfanos los autores principiantes.

No es de extrañar, pues, que muchos autores de la posguerra incurrieran en un realismo tradicional cuando no trasnochado, sobre todo si se tiene en cuenta que muchos de ellos se sentían llamados a mostrar en sus novelas lo que la España oficial trataba de escamotear con una retórica rimbombante: el terror del estado, el colaboracionismo de la Iglesia, el oportunismo de la burguesía, el atraso de grandes partes de la población, la pobreza, el hambre, la falsificación de la historia...

En los años sesenta muchos valores consagrados (Camilo José Cela, Miguel Delibes, Juan Goytisolo y muchos otros) se sacudieron el yugo del realismo social y retomaron el hilo de las innovaciones de la preguerra cortado por la dictadura. Es cierto que esto significó un 
gran paso hacia adelante para la narrativa, pero igual lo es que en un importante aspecto la narrativa seguía estancada, puesto que no cambió de temática: la narrativa seguía centrándose en -obsesionándose con- Ta España de la Guerra Civil y de la dictadura. Por mucho que la narrativa quisiera combatir la política y cultura oficiales - en un principio con su compromiso político, luego con su experimentalismo-, no pudo evitar ser, en cierto sentido, tan estrecha de miras como el régimen contra el que se rebelaba. Y si hábía una cosa que querían evitar las siguientes generaciones de autores, fue ser estrechas de miras. Hay que tener en cuenta que no habían vivido de forma consciente los primeros - y peores - años del franquismo, sino que habían crecido en una época en que iban abriéndose las puertas al extranjero, por más que el régimen intentara evitarlo. Se trata, pues, de autores que no estaban tan traumatizados por la guerra y sus consecuencias como las generaciones anteriores y que en su adôlescencia habían tenido más posibilidades de ampliar sus horizontes.

Eran éstas unas circunstancias muy favorables para que naciera una tenaz alergia a los tiempos y la situación en que esta generación de autores había crecido. Se podría decir, incluso, que para ellos el periodo del franquismo como tema literario se iba convirtiendo en poco menos que un tabú. Un ejemplo representativo sería Eduardo Mendoza, cuyas primeras cuatro novelas se agrupan alrededor de este episodio traumático y desdeñado de la historia reciente de España: La verdad sobre el caso Savolta (1975) y La ciudad de los prodigios (1986) tienen su acción en un periodo anterior a la Guerra Civil, El misterio de la cripta embrujada (1979) y El laberinto de las aceitunas (1982) durante la transición.

Unos pocos años después de haber terminado La ciudad de los prodigios, Mendoza dijo que vislumbraba un cambio a este respecto y que este vacío significativo estaba en vías de llenarse:

Yo creo [...] que hay ahora una generación, a la que yo pertenezco, que está llegando a la madurez, de la edad y de la profesionalidad, y que están empezando a contar su experiencia personal. Esta generación tiene la peculiaridad de ser la única generación del mundo que vivió el fascismo completamente, en todos sus ciclos. Nació dentro del fascismo, fue educada en el fascismo y lo vio envejecer y volverse caduco y ñoño y morir de muerte natural y dejar una herencia y transformarse de una militancia de banderas y tambores en una cosa mucho más sutil que seguía informando 
toda la vida pero que ya no necesitaba expresarse por medio de símbolos y estandartes. No tenía ni siquiera que exponer su filosofía porque ya estaba en la vida cotidiana, en la educación, en la información, en el lenguaje. Los que vivimos esta experiencia, [...] única en el mundo [...], tenemos este bagaje que nos ha marcado y que creo que es interesante empezar a contar. (Steenmeijer, "Barcelona" 11)

La pregunta que me propongo contestar aquí es hasta qué punto estos pronósticos de Mendoza se han materializado. Dicho de otra manera: ¿el periodo del franquismo ha dejado de ser un tabú para los autores de su generación? Intentaré esbozar una respuesta a base de un comentario de la obra de Eduardo Mendoza (1943) a partir de La ciudad de los prodigios, de Javier Marías (1951) y de Antonio Muñoz Molina (1956), que se encuentran entre los autores más productivos, polifacéticos y traducidos de la época postfranquista. ${ }^{1}$

\section{El caso Mendoza: la falta de urgencia}

Como cabía esperar en vistas de las afirmaciones arriba citadas, en la obra de Mendoza se ha producido un cambio notable: dos de las cuatro novelas que publicó después de La ciudad de los prodigios - El año del diluvio (1992) y Una comedia ligera (1996) - tienen como fondo la dictadura franquista. La primera novela evoca un mundo antiguo que está a punto de tener que renunciar a sus costumbres y tradiciones en favor de los nuevos tiempos que avanzan: el interior de Cataluña a principios de los años cincuenta, cuando, según la novela, el antiguo poder rural estaba en vías de extinción, los maquis aparecían como bandoleros románticos reinando en las montañas y el gobierno regional aún no se había hecho cargo de la sanidad. El tema de la modernidad que va invadiendo la vida tradicional está entretejido con la vida de sor Consuelo. Como madre superiora acaba de recibir el mando del necesitado hospital de un pequeño pueblo, que con la llegada de un hospital financiado por el Estado amenaza convertirse en un caso desahuciado. En busca de ayuda económica, llama a la puerta de Augusto Aixelà de Collbató, un cacique atractivo e indolente, el último descendiente sin hijos de una vieja familia de terratenientes, que simpatiza con el franquismo. 
En el curso de las arduas negociaciones con este aristócrata la monja ejemplar se da cuenta, con gran estupor, de que está enamorándose del cacique. La toma de conciencia de sus sentimientos y la consiguiente confusión mental se expresan de manera discreta y serena. Pero después de que la monja ha hecho el amor con el terrateniente, el ritmo de la novela se acelera bruscamente y los acontecimientos (unos aún más improbables que otros) y los géneros y subgéneros (novela sentimental, novela de guerra, novela política, novela de aventuras, novela psicológica, elegía rural, melodrama, culebrón) se entremezclan dando tumbos los unos sobre los otros. Por ser tan abrupto, brusco y extremado, este cambio no convence como representación icónica de la transición de tradición a modernidad, sino que convierte El año del diluvio en una caricatura indefinida e insatisfactoria.

Si la segunda mitad de El año del diluvio es abrumadora, Una comedia ligera se caracteriza precisamente por un ritmo lento. La novela tiene la extensión de La ciudad de los prodigios, y en cierto sentido puede ser considerada como una continuación de esta obra anterior. La historia transcurre a finales de los años cuarenta, cuando Barcelona había dejado de ser una ciudad de prodigios por algún tiempo ya. Sin darse ninguna prisa, Mendoza nos presenta al autor de comedias Carlos Prullàs merodeando durante un par de días por la capital catalana cortada del mundo. A poco măs de la mitad de la novela se produce el asesinato que alterará la vida de Prullàs y se descorre un poco el velo detrás del cual se esconde la Barcelona prohibida: la gente marginada, el hampa, las prostitutas, los estafadores, los autores disidentes, los conspiradores políticos. A partir de aquí Barcelona deja de ser una ciudad de una sola dimensión. También en la profesión de Prullàs las cosas dejan de ser lo que eran: sus comedias están pasando de moda, ya que ahora el público "pide ideas profundas y emociones fuertes: una nueva percepción de la realidad" (50), con lo que el autor parece aludir al existencialismo y el realismo social que iban a cambiar el clima cultural y literario del país. El autor de comedias es lo bastante oportunista como para extender el brazo hasta donde le llega la manga: deja su profesión y se convierte en un hombre de negocios.

Prullàs es una personalidad gris en una realidad gris $\mathrm{y}$, por consiguiente, un símbolo evidente de su tiempo. Sin embargo, el protagonista y la historia de la que forma parte son demasiado singulares como para considerar Una comedia ligera como la novela 
de un trauma colectivo. Diría incluso que su significado programático o metaliterario es mayor que su significado referencial. Sería exagerado, quizás, considerar a Prullàs como un alter ego de Mendoza, pero no lo es relacionar la falta de urgencia que transmite Una comedia ligera con las ideas programáticas afirmadas recientemente por el autor, según el cual la novela, por los cambios drásticos vividos por el género en el curso del siglo veinte (vanguardia, modernismo, postmodernismo), ha perdido mucho de su importancia. "Hoy la novela se ha convertido en una forma honesta, civilizada e instructiva de entretenimiento [...] y los lectores de novela, en simples consumidores de novela" ("La novela" 23). Sea como fuere, considerando el año de nacimiento de Mendoza — 1943_, es muy poco probable que el autor catalán haya querido ficcionalizar sus propias vivencias del franquismo en estas dos novelas ubicadas en la dictadura. En el fondo, pues, el enfoque y el planteamiento de El año del diluvio y Una comedia ligera no se distinguen de los de sus novelas anteriores.

\section{Un español a regañadientes: Javier Marías}

España brilla por su ausencia en la primera novela de Javier Marías, Los dominios del lobo, escrita en su mayor parte en el verano de 1969, cuando "el joven Marías" (dixit Juan Benet) - que aún no había cumplido dieciocho años- estuvo en París. El libro - una crónica de familia tan curiosa como cautivadora, escrita en un estilo muy transparente y llena de subintrigas - transcurre completamente en los Estados Unidos. El planteamiento de Marías fue insólito: para escribir Los dominios del lobo se había basado en no menos de ochenta y cinco películas - la gran mayoría de ellas norteamericanas de los años treinta, cuarenta y cincuenta- que había visto en París durante las seis semanas que estuvo allí. El caso es que Marías estaba seguro de una cosa cuando se escapó a París, como escribe en el prólogo que añadió a una edición posterior:

[...] yo no deseaba escribir necesariamente sobre España ni necesariamente como un novelista español. Las razones para este rechazo (tan global como injusto) eran de orden literario y de orden político, pero no es este el lugar para exponerlas ni para refutarlas. Sólo quiero llamar la atención sobre el hecho de que este desdén inicial por lo español (en tanto que identificado 
simplistamente con lo franquista) lo compartía con la mayoría de los miembros de mi generación - la primera nacida después de 1939—, según pronto averigüé. (11)

Los dominios del lobo no es representativa de las novelas con las que luego iba a consagrarse Marías, pero con respecto a este rechazo de lo español (y no sólo "identificado simplistamente con lo franquista") el autor madrileño ha seguido siendo fiel, en esencia, a la poética de su primera novela. Es cierto que los protagonistas/narradores hiperconscientes de novelas como Todas las almas, Corazón tan blanco y Mañana después de la batalla piensa en mí tienen la nacionalidad española, pero se trata de un hecho de poca importancia en el contexto de sus "relatos", que no tratan de España sino que transmiten un singular sentimiento de vida, una manera muy particular de pensar, un lenguaje y estilo muy propios y, al mismo tiempo, universales. Los narradores de Marías son solipsistas empedernidos que prefieren mantenerse a cierta distancia de la vida, incluida la propia. Estos voyeurs de la existencia no paran de dialogar consigo mismo, construyendo así una imponente fortaleza de historias, observaciones, razonamientos y explicaciones alrededor de ellos mismos tras la cual se atrincheran. Pero por grandes que sean sus capacidades verbales, su retórica, su perspicacia y sus mecanismos de defensa, no pueden, empero, evitar que su conciencia sea invadida por la sensación inquietante y ominosa de que la existencia humana en general y la suya en particular abarca mucho más de lo que ellos pueden dominar y quieren saber. Por más que prefieran que no fuera así, resulta que, al fin y al cabo, ellos no son capaces de seguir manteniéndose a una distancia superior de ese fenómeno caprichoso e imposible de controlar que es la vida.

Pero en la impresionante serie de novelas y libros de cuentos en que da cuerpo a esta fascinante temática, el propio Marías sí ha sabido guardar distancia del tema de "España como problema". Hay que destacar que se trata de una cuestión estética y no moral. No es que Marías crea que España es por definición un tema inferior o sin interés, sino que se presta más al ensayo que a la novela. (Ver Steenmeijer, "Bedriegen".)

Marías -que también como ensayista y columnista tiene una gran reputación - habla con conocimiento de causa puesto que muchos de sus ensayos y columnas se centran en "España como problema", y en ellos Marías sí se revela como un autor comprometido. Con su 
despiadada crítica de las manías y malas costumbres de sus compatriotas, Marías forma parte de una tradición literaria muy española, aunque sea a pesar suyo: la de Quevedo, Larra, Clarín, Valle-Inclán y otros españoles a regañadientes.

Quien lee las columnas reunidas en Mano de sombra (1997) y Seré amado cuando falte (1999) no tiene más remedio que concluir que hay pocas cosas en España que funcionan. Asignándose a sí mismo el papel del gentleman, Marías denuncia los abusos menores y mayores de sus compatriotas en, entre otras cosas, la política, la justicia, la organización penitenciaria, Telefónica, Correos, la vida pública, los modales, el lenguaje contemporáneo, la manera de vestir (¡la proliferación de varones que, en verano, lucen sin verguienza alguna un pantalón corto en plena ciudad!). Llama la atención la manera directa en que Marías muestra y expresa sus alergias e irritaciones ( $y$, dicho sea de paso, también sus afinidades y pasiones). Se trata de una diferencia llamativa entre el columnista y el novelista: en sus obras periodísticas hay apenas un rastro de la actitud y la manera de formular circunspectas y reservadas tan características de novelas como Corazón tan blanco y Mañana después de la batalla piensa en mí. En aquéllas no tiene la palabra un narrador distante sino un escritor que busca el contacto con sus lectores.

Marías muestra mayor indignación cuando monta en cólera contra maneras de pensar y proceder intolerantes, como el terror de ETA, o los excesos de la praxis del lenguaje políticamente correcto; o bien contra disposiciones de tendencia totalitaria, como la ley aprobada hace algunos años en Alemania, que autoriza al Estado a practicar escuchas telefónicas y vigilancias electrónicas. Las raíces de esta alergia a la intolerancia hay que buscarlas en la época franquista, como queda claro, por ejemplo, en la columna "No los quiero" (en Mano 126-28). Marías hace migas de los columnistas y periodistas que se atreven a comparar el régimen franquista y el socialista (todavía en el poder por aquel entonces) y que, además, no dudan en concluir que aquél es de preferir a éste. No es que el autor se ponga a defender al gobierno socialista, pero sí sale en defensa del sistema en que funciona y por el cual en un futuro próximo los socialistas estarán obligados a dar paso a otro gobierno. Es inadmisible, escribe Marías, que

la gente con más de treinta y cinco años haya olvidado (o lo finja) que durante el franquismo lo único seguro era que nunca iba a haber elecciones 
y que aquel dictador se marcharía sólo cuando lo decidiera su apacible muerte, como así fue. No era cuestión de esperar uno o dos o tres años, sino indefinidamente, de algunas generaciones se llevó la vida entera. (127)

Después de la Guerra Civil se extinguió de forma sistemática a los adversarios del nuevo régimen, la prensa sólo podía escribir lo que le dictaba el régimen y el sistema era "corrupto desde el primero hasta el último día y desde el Jefe del Estado hasta el más breve de sus ministros, gobernadores o alcaldes [...]" (127).

Después de estas comprobaciones sigue un pasaje muy emocional lleno de recuerdos traumáticos de los años del franquismo vividos por el propio Marías (los años sesenta y primeros setenta): la arbitrariedad con que se detenía e interrogaba a la gente, la impunidad con que se retenía a la gente indefinidamente, la retórica cruel, cínica, vulgar y despótica de la que se servía el régimen, la represión de las formas más inocentes de la diversión, "el miedo perpetuo con el que vivíamos y dormíamos" (128).

"Teníamos dieciocho años", dice Marías concluyendo esta letanía, para terminar su artículo con vehemencia:

No me digan que estamos peor que entonces., no me digan que era más leve y honrado el franquismo, no me digan que nada de lo que hoy sucede es más corrupto o criminal que aquello, no me digan que vuelvo a tener dieciocho años. No es verdad, y no los quiero. (128)

Un artículo aparecido en El País, "El artículo más iluso", atestigua asimismo una gran indignación moral provocada por la manera en que algunos enfocan el pasado franquista. Característica del clima moral en España es, según Marías, la falta de vergüenza con que algunos españoles prominentes disculpan su actitud $\mathrm{y}$ comportamiento durante la época franquista. Ni esconden ni niegan lo que han hecho (o lo que han dejado de hacer) sino que lo admiten abiertamente, convencidos de que, en el fondo, no han hecho nada malo. Como primer ejemplo Marías menciona a un filósofo conocido, que durante un curso de verano dijo que durante años había sido "obligado" a espiar a sus colegas y, llegado el caso, a denunciarlos. El segundo ejemplo se refiere a un columnista que, contestando al descubrimiento de sus elogios del régimen franquista, dijo: "Lo que deseaba, y deseo, es sobrevivir, y a veces hay que cambiar el gesto para seguir adelante, uno tiene que plegarse a ciertas 
condiciones y personas" (cit. en Marías, "El artículo más iluso" 16). En el tercer caso se trata de un novelista muy conocido que en los años cuarenta trabajó de censor. "Me hice censor para poder comer, para tener un mínimo sueldo... Entonces no había una perra para nadie". Marías no menciona ningún nombre en su artículo pero es obvio que el autor aludía a José Luis L. Aranguren, Eduardo Haro Tecglen y Camilo José Cela.

Por no haber vivido la Guerra Civil y la primera época de la posguerra - la más difícil y la más dura- Marías apenas se considera autorizado para juzgar de lo que entonces se hizo y escribió. "Ninguno podemos saber a ciencia cierta cómo habríamos obrado en aquellas circunstancias, acaso habríamos incurrido en bajezas mayores, quién sabe" (16). Pero más que los propios actos inaceptables, lo que le importa a Marías es la justificación alegada muchos años después por el filósofo, el columnista y el novelista sin mostrar ni una pizca de vergüenza, de arrepentimiento o de remordimiento: no había otra opción, todo el mundo lo hacía. Y eso es absolutamente falso, dice un Marías indignadísimo, reivindicando con una fuerte carga emocional el recuerdo de "los de otra pasta":

Por mucho que intenten y les convenga olvidarse, también los hubo mejores. O simplemente $-y$ vuelvo a las palabras en desuso, antiguasmás rectos, o más dignos, o más resistentes, o más orgullosos, o más escépticos, o más asqueados, o más derrotados, no sé: aquéllos a los que no quedaron acaso fuerzas ni ánimo para desear más nada, ni sobrevivir. Que sobreviva su memoria al menos, que no se borre su triste y languideciente o pasada existencia, por incómoda que resulte a los vivos o supervivientes que hacia ese espejo mejor, sin azogue y espectral y resquebrajado, nunca quieren ni se dignan mirar. (16)

Hubo muchas reacciones, también desde círculos académicos. ${ }^{2} \mathrm{Se}$ recalcó la necesidad de un debate sobre el pasado comentado por Marías pero se reprochaba al autor una falta de comprensión por las circunstancias en que procedían el filósofo, el columnista y el novelista. El reparo me parece injusto, puesto que la crítica de Marías no concernía su actitud por aquel entonces sino su justificación posterior. No me parece improbable que el propio autor interprete estas reacciones como otra prueba de la tesis que formuló al principio de "El artículo más iluso": que la moral está muy mal en España. 


\section{Antonio Muñoz Molina: la promesa de la novela de una generación}

Antonio Muñoz Molina es otro autor/columnista que se pasma y enfada por lo que no vacila en llamar la barbarie de la España contemporánea, donde "[...] con el paso del tiempo, uno se va acostumbrando desengañadamente a que la legalidad y la justicia sean tan dudosas como en un [sic] república tropical regida por caciques y narcotraficantes [...]" ("La compasión" 106). No suele haber ironía en las afirmaciones aceradas hechas en las columnas en que el autor andaluz denuncia abusos en la política y la justicia, no dudando en contarlo con pelos y señales.

El compromiso moral de Muñoz Molina se palpa, asimismo, en Plenilunio (1997), su última novela propiamente dicha. La intriga se centra en la investigación de una violación y el asesinato de una chica de nueve años y otro intento de repetir estos crímenes poco tiempo después. Con horripilante lujo de detalles se describen los actos y los pensamientos del pervertido autor de los crímenes, lo que no deja de provocar un previsible efecto en el lector. Pero todo ello es de importancia secundaria, puesto que los protagonistas no son las víctimas y el violador/asesino sino la maestra de la chica asesinada y el inspector que dirige la investigación. Ambos, aturdidos por los fuertes golpes que han sufrido en el curso de su vida, recobran su conciencia y sensibilidad a causa de la violación bárbara y fatal del inocente germen de vida que era la chica, y se ven confrontados con sus propios traumas, que habían reprimido durante muchos años.

El inspector, crecido en la ciudad andaluza a la cual acaba de volver, había tenido que trabajar en Bilbao, donde él y su esposa continuamente recibían amenazas de muerte y donde el propio inspector tambien se había pasado de la raya más de una vez. Esta situación esquizofrénica - víctima y verdugo se reúnen en una misma persona - se parece a la de su juventud y adolescencia: por un lado son lastimosas las circunstancias en que creció (un padre preso por sus ideas comunistas, una madre muy enferma y pobre que no podía ocuparse de él), pero por el otro son censurables sus actividades como informante de la Dirección General de Seguridad.

Todo este pasado arrinconado surge durante las intensas conversaciones que el inspector tiene con el padre Orduña, su antiguo maestro y protector al que no había visto por varias décadas. Este 
cura rojo tampoco tiene la conciencia en paz. Durante la Guerra Civil luchó con los nacionales, y después de la guerra maltrató físicamente y mentalmente a sus alumnos.

No creo que lo más importante sea que el lector llegue a un juicio moral sobre la actitud y los actos de estos dos personajes, sino que se forme una idea del laberinto moral en que el inspector y la maestra se encuentran y la lucha que libran consigo mismos. En cualquier caso, la intención ética es considerablemente mayor en Plenilunio que en las novelas anteriores de Muñoz Molina. Igual que aquélla, éstas se centran en la presencia del pasado, pero en un marco muy distinto: el contraste (o la falta de él) entre la ficción y la realidad. Así, el diálogo entre pasado y presente en Beatus Ille (1986) y Beltenebros (1989) no lleva al lector a un laberinto moral sino a un laberinto ontológico. En estas novelas no se pone en juego la conciencia de los personajes sino su percepción de la realidad. Ambas se desarrollan en la época franquista pero remiten más a Eco y Borges que a un periodo histórico concreto.

En El jinete polaco (1991) hay más referencias a la Historia. La novela es una amalgama de historias y anécdotas sobre los habitantes de Mágina, una ciudad provinciana que tiene mucho en común con Úbeda, la ciudad donde nació y creció Muñoz Molina. Engloba unos ciento veinticinco años de historia local, incluyendo la dictadura franquista. Pero en esta novela el pasado está al servicio del "presente absoluto" que dos amantes que acaban de conocerse tratan de crear durante el idilio abrumador que viven a miles de kilómetros de su tierra de origen: Mágina, una ciudad provinciana en el interior de Andalucía. En los dieciocho años después de su salida de Mágina, Manuel, el alter ego de Muñoz Molina, se ha convertido en un extranjero, un nómada. También Nadia - hija de un republicano exiliado- lucha con su desarraigo. Las tradiciones y las historias de Mágina, que sus antepasados llevaban en la sangre, ya no son una evidencia para ellos sino más bien un anhelo. Pero no pueden dar marcha atrás al reloj, no sólo porque los dos treintañeros mismos han cambiado, sino también porque su ciudad de origen se ha modernizado. De ahí que recurran a la imaginación y, a base de una vieja colección de fotos, traten de (re)construir el pasado. La abundancia de historias y anécdotas en que resultan sus esfuerzos revela que lo que parece ser un pasado pretérito e irrecuperable puede tener un gran significado e importancia para quienes han llegado a formar parte de la aldea global. 
Como ya queda dicho, el pasado (re)construido engloba un periodo mucho mayor que el periodo franquista. En la última fase de este periodo, Manuel - adolescente - soñaba ante todo con un futuro lleno de aventura fuera de España: como escritor en París con una novia del norte de Europa, o como batería en un grupo de rock entre los hippies en San Francisco. Este deseo en sí no era, claro está, típico de la (última fase de la) España franquista, pero la intensidad y el desfase sí lo eran. "We want the world and we want it now," cantaba Jim Morrison. Pero el cantante de los Doors ya había muerto algunos años antes de que estas palabras incitaran la fantasía de Manuel. Lo mismo vale para Jimi Hendrix, Janis Joplin y Otis Redding, mientras que los Beatles ya se habían separado unos años antes. Este desengaño parece valer para toda una generación o incluso todo un país: "Íbamos a llegar tarde al mundo, pero no lo sabíamos, nos preparábamos avariciosamente para asistir a una fiesta que ya había terminado [...]" (346).

Dieciocho años después, Manuel, convertido en un ciudadano del mundo moderno pero frustrado, vuelve a sentir la necesidad de completar su existencia a través de su imaginación, pero esta vez ésta se dirige en sentido contrario - tanto con respecto al tiempo (el pasado en vez del futuro) como al espacio (su tierra natal en vez del extranjero)-, lo cual puede interpretarse como un indicio de que se ha liberado de su tendencia a idealizar lo extranjero y lo moderno.

La novela corta El dueño del secreto (1994) se desarrolla en el invierno y la primavera de 1974 y tiene como tema una conspiración para derribar el régimen franquista. Para su asombro, un joven estudiante andaluz que acaba de llegar a Madrid se ve implicado en ella. Con ello, se materializa de la noche a la mañana la existencia apasionante y aventurera que anhelaba. Poco después se descubre la conspiración, porque este "marxista pusilánime y más bien imaginario", lleno de un entusiasmo que quiere compartir, ha hablado más de la cuenta.

Unos veinte años después, el conspirador fracasado, regresado definitivamente a la existencia anodina de donde procedía, recuerda este episodio clave de su vida, comentando el clima gris, represivo y sin perspectiva de aquellos tiempos.

Nuestra generación [...] fue la última en llegar al antifranquismo, y nos tocó la paradoja de heredar, con dieciocho años, la tradición de la derrota de las generaciones anteriores, de respirar un aire enrarecido por treinta y 
tantos años de desaliento y de invenciones gloriosas y absurdas de huelgas generales que no fueron vencidas porque nunca llegaron a existir. (95)

Sería exagerado, sin embargo, llamar El dueño del secreto la novela de una generación, puesto que el protagonista es más bien atípico. Es el polo opuesto de Manuel de El jinete polaco, que en la misma época y a la misma edad cambió lo antiguo por lo moderno, pero que no volvió sobre sus pasos poco tiempo después y que, por consiguiente, es mucho más representativo del desarrollo que vivió España en las últimas décadas del siglo pasado. Además, el yo narrador de El dueño del secreto no quiere mantener vivo el recuerdo de su estancia en Madrid por motivos ideológicos o morales -es decir, colectivos - sino por motivos psicológicos, o sea particulares: los meses de la conspiración forman el único episodio de su vida en que al menos parecía haber una posibilidad de que su existencia diera un giro aventurado y apasionante. El recuerdo de la conspiración contra Franco ha llegado a ser el único consuelo en su vida anodina.

\section{Conclusiones}

Antonio Muñoz Molina es el único de los tres autores comentados aquí que en su obra nunca ha "eludido" el franquismo vivido por él. Es significativo que sea, asimismo, el más joven de los tres y haya empezado a escribir bastante tiempo después de la muerte de Franco. En sentido práctico y programático el periodo franquista apenas puede haber sido un impedimento para él, puesto que la censura ya había sido abolida cuando concebió sus primeros proyectos literarios, mientras que el ajuste de cuentas con el realismo social ya había sido realizado unos diez años antes de que apareciera su primera novela.

A lo sumo, la época franquista puede haber marcado la poética y la temática de su obra en sentido existencial, como sugieren, ante todo, los elementos autobiográficos en El jinete polaco. Sea como fuere, ninguna de las novelas que Muñoz Molina ha publicado hasta la fecha se centra en la vivencia del franquismo, por lo menos no en el sentido autobiográfico a que aludía Mendoza en las afirmaciones antes citadas hablando del "trauma" único de los autores nacidos y crecidos en el franquismo. Pero no me parece improbable que en un futuro próximo Muñoz Molina escriba una novela centrada en el franquismo vivido por él mismo, no sólo porque los años franquistas nunca han sido un 
problema literario-programático para él sino también porque en Plenilunio parece haberse despedido de la manera modernista o postmodernista con que había entablado el diálogo entre pasado y presente en sus novelas anteriores para interesarse más por las implicaciones morales de este diálogo o enfrentamiento.

En su narrativa, el propio Mendoza ha mostrado mucho menos interés por esta temática de lo que cabía esperar en vista de sus afirmaciones al respecto, mientras que Marías la considera demasiado poco literaria (jy demasiado española!) como para elaborarla en su ficción. La poética de Mendoza y la de Marías son muy distintas y casi diría opuestas: anécdota frente a reflexión, aventura frente a (auto)contemplación, discurso leve frente a discurso solemne. Pero tienen en común una cosa: la falta de ganas (o de voluntad o de capacidad) de ficcionalizar las propias vivencias y observaciones en la dictadura.

Considerando la obra de los tres autores comentados aquí, sería apropiado concluir que los pronósticos de Mendoza apenas se han hecho realidad. Sólo en el caso de Muñoz Molina - quien pertenece a la última generación (es decir, la menos traumatizada) de los autores que vivieron el franquismo_ parece que tendrá razón Mendoza. Por lo que respecta a las generaciones posteriores, a ellos sólo les queda la posibilidad de ficcionalizar el periodo franquista por vía de la documentación y la imaginación, puesto que no lo conocen por propia experiencia. Parece poco probable, sin embargo, que autores como José Ángel Mañas, Ray Loriga y David Trueba aprovechen esta oportunidad. Están demasiado ocupados con la España hedonista en que viven como para interesarse por el pasado reciente. No sería descabellado, a mi juicio, sospechar que en esta actitud resuena, asimismo, el rechazo o negación de la España franquista tan característico de la narrativa de sus antepasados inmediatos.

\section{Notas}

1. Un ejemplo atípico sería la obra de Álvaro Pombo (1939), que merece un estudio aparte. También hay que mencionar aquí a Manuel Vázquez Montalbán (1939), que ya en El pianista (1985) había ficcionalizado episodios del franquismo 
que él mismo había vivido y que luego siguió esta huella en Galíndez (1990) y Autobiografía del general Franco (1992). Hace falta recordar, empero, que el novelista tardó bastante en acercarse a esa época. Lo mismo vale para Félix de Azúa (1944), que en Historia de un idiota contada por él mismo (1986) convirtió en ficción sus vivencias en (y después de) el franquismo. El autor catalán acaba de publicar Momentos decisivos (2000), que se desarrolla en un ambiente y época muy bien conocidos por él (la Barcelona de principios de los años sesenta). No son más que algunos ejemplos que más que desmentir la tendencia estudiada aquí la matizan.

2. Ver, entre otras: "Réplicas", carta de Javier Muguerza (El País 3 de julio, 1999: 13-14); "Con desagrado respondo", carta de Javier Marías (El País 10 de julio, 1999: 13-14); "Que el lector juzgue", carta de Eduardo López-Aranguren y sus hermanos y hermanas (El País 17 de julio, 1999: 11-12); "Por alusiones", carta de Javier Muguerza (El Pais 17 de julio, 1999: 12); "Con hastío respondo", carta de Javier Marías (El País 24 de julio, 1999: 9-10); Santos Juliá, "Rastros del pasado" (El País 25 de julio, 1999: 15); Fernando Vallespín, "Pretérito imperfecto" (El País 25 de julio, 1999: 15); "En algo estamos de acuerdo", carta de José Luis López-Aranguren y sus hermanas y hermanos (El País 31 de julio, 1999: 11-12); "Con desaliento respondo", carta de Javier Muguerza (El País 31 de julio, 1999: 12); Javier Tusell, "La memoria y el encono" (El País 11 de septiembre, 1999).

\section{Obras Citadas}

Marías, Javier. "El artículo más iluso." El País 26 de junio, 1999: 15-16.

- Corazón tan blanco. Barcelona: Anagrama, 1992.

—. El dominio del lobo. Barcelona: Anagrama, 1996.

-. Mano de sombra. Madrid: Alfaguara, 1997.

—. Mañana en la batalla piensa en mí. Barcelona: Anagrama, 1994.

—. Seré amado cuando falte. Madrid: Alfaguara, 1999.

_. Todas las almas. Barcelona: Anagrama, 1989.

Mendoza, Eduardo. El año del diluvio. Barcelona: Seix Barral, 1992.

—. La ciudad de los prodigios. Barcelona: Seix Barral, 1986.

—. Una comedia ligera. Barcelona: Seix Barral, 1996.

___. El laberinto de las aceitunas. Biblioteca de Bolsillo. Barcelona: Seix Barral, 1987.

—. El misterio de la cripta embrujada. Biblioteca de Bolsillo. Barcelona: Seix Barral, 1987. 
—_. "La novela se queda sin épica." El País 16 de agosto, 1998: 23-24.

—. La verdad sobre el caso Savolta. Biblioteca de Bolsillo. Barcelona: Seix Barral, 1983.

Muñoz Molina, Antonio. Beatus Ille. Barcelona: Seix Barral, 1993.

—. Beltenebros. Barcelona: Seix Barral, 1993.

—. "La compasión." El País Semanal 14 de febrero, 1999: 106.

—. El dueño del secreto. Madrid: Ollero y Ramos, 1994.

—. El jinete polaco. Barcelona: Planeta, 1991.

. Plenilunio. Madrid: Alfaguara, 1997.

Preston, Paul. Franco. A Biography. London: HarperCollins, 1993.

Steenmeijer, Maarten. "Barcelona heeft iets wat andere steden niet hebben.

Eduardo Mendoza over zijn boek De stad der wonderen." Vrij Nederland/Boekenbijlage 18 de junio, 1988: 11-12.

—_. "Bedriegen zit in onze natuur. Gesprek met Javier Marías." Vrij Nederland 11 de enero, 1997: 74-75. 